\title{
Avaliação do emprego de casca de eucalipto na biossorção de hidrocarbonetos leves de petróleo contaminante em corpos hídricos simulados
}

\section{Evaluation of the employment of eucalyptus bark in the bioadsorption of contaminant petroleum light hydrocarbons in simulated water bodies}

\author{
Ricardo Adriano Dorledo de Faria ${ }^{1}$, Renata Braga Soares ${ }^{1}$ \\ Christianne Garcia Rodrigues ${ }^{2}$
}

\author{
${ }^{1}$ Universidade Federal de Minas Gerais - UFMG. Departamento de Engenharia Química, Av. Presidente Antônio Carlos, \\ 6627, CEP 31270-901, Belo Horizonte, Minas Gerais, Brasil. \\ ${ }^{2}$ Centro Universitário de Belo Horizonte - UniBH. Instituto de Engenharia e Tecnologia, Av. Professor Mário Werneck, \\ 1480, CEP 30455-610, Belo Horizonte, Minas Gerais, Brasil. \\ e-mail: ricardo.adriano08@hotmail.com, renatabragasoares@yahoo.com.br, christianne.garcia@unibh.br
}

\begin{abstract}
RESUMO
A contaminação de corpos hídricos por petróleo e seus derivados tem sido um dos principais problemas ambientais da atualidade e causa prejuízos diversos, como o desequilíbrio ecológico pelos danos à fauna e flora e a redução da disponibilidade de luz solar no meio aquático. Diante desse contexto, este trabalho propôs o emprego de casca de eucalipto para a eliminação de hidrocarbonetos leves de petróleo (gasolina comercial do tipo C) contaminantes em ambientes simulados de água doce e água salgada. Para tanto, foi verificada a capacidade de a casca adsorver compostos orgânicos quando submetida ao contato com os corantes amarelo tartrazina, rodamina $\mathrm{B}$ e azul de metileno, tendo os dois últimos confirmado a afinidade química do biomaterial com compostos de carbono. Em seguida, na adsorção de hidrocarbonetos leves da solução contaminante simulada, foram avaliadas as influências: da granulometria da biomassa, pela qual se observou a tendência de melhor adsorção com o menor tamanho de partícula do material, a temperatura do corpo hídrico, que não afetou consideravelmente a capacidade de adsorção, e o tempo de reação, que beneficiou a biossorção em ambiente de água doce e desfavoreceu quando a biomassa esteve em contato com água salgada. Além disso, numa comparação da casca de eucalipto com outros adsorventes comerciais (carvão ativo, vermiculita e terra diatomácea), essa teve capacidade de adsorção superior aos demais, mostrando-se ser um material promissor para a descontaminação de águas contendo hidrocarbonetos de petróleo.
\end{abstract}

Palavras-chave: Casca de eucalipto, biossorção, petróleo.

\section{ABSTRACT}

The contamination of water bodies by petroleum and its derivatives has been one of the main environmental problems nowadays and it causes many losses, such as ecological imbalance by damage to fauna and flora, and the reduction of the sunlight availability in the aquatic environment. Given this context, this paper proposed the employing of eucalyptus bark for the removal of petroleum light hydrocarbons (commercial gasoline type C) contaminant in simulated freshwater and saltwater environments. Therefore, it was verified the bark ability in adsorbing organic compounds when it was submitted to the contact with tartrazine, rhodamine $\mathrm{B}$ and methylene blue dyes, and the latter two had confirmed the chemical affinity of the biomaterial with carbon compounds. Then, in the adsorption of the simulated contaminant solution, it was evaluated the influences of: the biomass particle size, observing a trend toward better adsorption with the smallest particle size of the material, the water body temperature, that did not appreciably affect the adsorption capacity, and the reaction time, which benefited the adsorption in freshwater environment and reduced when the biomass was in contact with the saltwater. Furthermore, in a comparison among eucalyptus bark and other commercial 
adsorbents (activated charcoal, vermiculite and diatomaceous earth), it had higher adsorption capacity than all of them, proving to be a promising material for the decontamination of water containing petroleum hydrocarbons

Keywords: Eucalyptus bark, bioadsorption, petroleum.

\section{INTRODUÇÃO}

Com o crescente aumento do contingente populacional, a demanda energética mundial também tende a aumentar e este fenômeno está intimamente relacionado ao consumo de petróleo. Uma previsão para o ano de 2040 indica um aumento de aproximadamente $40 \%$ da demanda por energia primária no planeta, levando a um consumo total de 382 milhões de barris de óleo por dia segundo a Organization of the Petroleum Exporting Countries (OPEC) [1]. No ano de 2014 o Brasil foi classificado como $15^{\circ}$ país com maior número de reservas de petróleo no mundo, sendo contabilizadas no ano seguinte um total de 24,4 bilhões de barris [2].

Na contramão da evolução do consumo de óleo, no entanto, destacam-se os graves problemas ambientais causados pela atividade petroleira. Desastres reportados mundialmente, como o derramamento no Golfo do México em 2010, chamam atenção para a gravidade deste problema, que pode afetar flora e fauna das regiões atingidas, bem como a vida de populações que habitam as proximidades dessas áreas [3, 4].

De um modo geral, a contaminação de águas por óleos e graxas dificulta a aeração e a iluminação natural de cursos receptores. Tal fato se dá em função da formação de um filme superficial insolúvel sobre a água, o que causa efeitos nocivos à fauna e flora, eleva os níveis de ozônio e diminui a qualidade do ar [5,6].

Souza et al. [7] destacam que efluentes contaminados por derivados de petróleo, como águas residuais da indústria de corantes e tintas, também são potenciais poluentes do meio ambiente, e a remoção desses compostos orgânicos tem se apresentado como grande desafio tecnológico. BONI et al. [8], que utilizaram bagaço de cana-de-açúcar para recuperação de efluente aquoso contaminado por derivados de petróleo, ressaltam que dentre variadas técnicas empregadas para a remoção de substâncias orgânicas tóxicas em corpos hídricos, a adsorção é a melhor opção especialmente em virtude de sua facilidade de operação e universalidade. No ramo da adsorção, uma alternativa que se destaca na remoção de óleos e graxas é a biossorção, termo que se refere ao tratamento de correntes aquosas com o emprego de biomassas encontradas na natureza ou provenientes de algum processo industrial. Esse processo dispõe de materiais abundantes no ambiente, que têm baixo custo de aquisição, apresentam alta lipofilidade, não necessitam ser regenerados após o uso, ao passo que podem ser utilizados para a produção de energia depois da aplicação no tratamento do efluente, e se tornam um produto de alto valor agregado, ocasionando destino sustentável ao resíduo industrial [9].

Costa et al. [10] investigaram o uso de bagacilho de cana-de-açúcar para tratar efluente sintético contaminado por petróleo bruto e constataram uma remoção de óleo de até $80 \%$ utilizando esta biomassa. Considerando os prejuízos causados pela presença de contaminantes orgânicos do petróleo em corpos hídricos, Santos et al. [11] estudaram o desempenho de quatro biomassas na bioadsorção de hidrocarbonetos leves presentes em efluente sintético simulado com gasolina comercial: sabugo de milho, serragem de madeira, mesocarpo de coco e bagaço de cana, verificando adsorções da ordem de até $12 \mathrm{~mL} \cdot \mathrm{g}^{-1}$. Ainda, destacando o baixo custo das biomassas aplicáveis a processos adsortivos, Younis et al. [12] verificaram a eficiência de casca de arroz na remoção de hidrocarbonetos policíclicos aromáticos advindos da indústria petrolífera.

Neste contexto, o objetivo deste estudo foi investigar a viabilidade da utilização de casca de eucalipto para a biossorção de hidrocarbonetos leves presentes em efluentes contaminados por derivado de petróleo (gasolina comercial), o que se justifica devido ao fato de que, segundo a Associação Brasileira de Produtores de Florestas Plantadas (ABRAF) [13], o eucalipto é a espécie mais plantada em florestas comerciais no Brasil, e, aliado a isso, a exploração comercial de madeira é atividade que gera grande quantidade de resíduos, podendo as cascas corresponderem de 9 a $20 \%$ do peso total da árvore. O uso de eucalipto e seus resíduos provenientes da atividade de silvicultura são comumente reportados na literatura principalmente para o emprego na adsorção de corantes orgânicos $[14,15,16]$ e de metais pesados [17, 18, 19, 20, 21]. Todavia, pouco se tem elucidado a respeito da capacidade desta biomassa em adsorver hidrocarbonetos leves de petróleo, como aqueles oriundos de combustíveis, mesmo se tratando de um material lignocelulósico [22], cujas características hidrofóbicas o apontam como promissor adsorvente de compostos orgânicos apolares [8].

\section{MATERIAIS E MÉTODOS}

\subsection{Preparo da biomassa}

A casca de eucalipto utilizada nesta pesquisa foi cedida pela empresa Plantar S/A Planejamento, Técnica e Administração de Reflorestamento (Curvelo/MG). A preparação da biomassa envolveu a dilaceração das cascas, bem como sua secagem ao ar livre durante três semanas. Em seguida, foi seca em estufa com circula- 
ção de ar forçada da marca Tecnal modelo TE-394/4 a $45^{\circ} \mathrm{C}$ por tempo suficiente para a completa remoção da umidade, o que foi constatado por variadas aferições de sua massa ao longo do período de secagem.

Uma vez seca, a biomassa foi submetida a trituração num liquidificador industrial Metvisa modelo LQ-10 ( $\mathrm{N}^{\circ}$ 5510) e a análise granulométrica em um agitador de peneiras eletromecânico da marca Solotest numa frequência de $10 \mathrm{~Hz}$ por 40 minutos em série Tyler com peneiras de 4, 8, 28 e 50 mesh (cujas aberturas de malhas correspondem, respectivamente, a 4,75 mm, 2,36 mm, 0,6 mm e 0,3 mm) e um coletor de finos.

\subsection{Caracterização do adsorvente}

Neste trabalho foi empregado o método das divisões sucessivas descrito por Brandão [23] para a amostragem da biomassa. O procedimento consistiu em formar com a casca de eucalipto um empilhamento na forma de cone uniforme sobre uma superfície linear. Em seguida, o material teve seu topo achatado e foi dividido em quatro partes iguais, quando um par das quartas opostas foi rejeitado e o remanescente foi misturado. Com esse, formou-se um novo cone, com o qual se repetiu todo o procedimento até a obtenção do tamanho de amostra desejado.

Amostras de casca de eucalipto de granulometria de 4 mesh foram analisadas num microscópio eletrônico de varredura modelo JSM-5310. Antes da análise o material foi recoberto por deposição de íons metálicos de ouro $(\mathrm{Au})$ a fim de se tornar condutor elétrico, dada a necessidade de interação do feixe eletrônico com a amostra. Foram obtidas imagens com ampliação de 350, 500, 750 e 1500 vezes.

Área superficial específica, volume médio de poros e diâmetro médio de poros foram estimados por meio das isotermas de adsorção e dessorção de $\mathrm{N}_{2(\mathrm{~g})}$ a $77 \mathrm{~K}$ pelo método de Braunauer, Emmet e Teller (BET), usando um equipamento NOVA-2200 BET analisador da Quantachrome Corporation, EUA. O experimento foi conduzido no Centro de Desenvolvimento da Tecnologia Nuclear - CDTN (Belo Horizonte/MG).

\subsection{Preparo do contaminante simulado}

O estudo foi conduzido em dois diferentes meios de contaminação simulada de petróleo, um em água doce outro em água salgada. Para a obtenção de água doce, amostra de água do Rio das Velhas foi coletada em trecho localizado no Distrito de Honório Bicalho/MG, tendo sido observados os princípios descritos no Standard Methods for the Examination of Water and Wastewater [24]. A coleta foi realizada em recipientes Whirl-Pak Thio-Bag® (Nasco), seguindo-se a metodologia apontada pelo fabricante e, em seguida, as amostras foram acondicionadas em caixa de isopor contendo gelo para preservação das características originais da água do rio até o momento das análises laboratoriais

Para os estudos com água do mar, foi preparada solução sintética que simula as características dos ambientes marinhos em conformidade com procedimento descrito pela American Society for Testing and Materials (ASTM), na Norma ASTM D-1141/98 [25], sendo preparadas as soluções-estoque I e II, cujas composições são expressas nas Tabelas 1 e 2 respectivamente.

Tabela 1: composição da solução-estoque i para preparo de água do mar artificial [25]

\begin{tabular}{c|c}
\hline REAGENTE & CONCENTRAÇÃO (g. $\left.\mathbf{L}^{-1}\right)$ \\
\hline $\mathrm{MgCl}_{2} \cdot 6 \mathrm{H}_{2} \mathrm{O}$ & 555,6 \\
\hline $\mathrm{CaCl}_{2}$ (anidro) & 57,9 \\
\hline $\mathrm{SrCl}_{2} \cdot 6 \mathrm{H}_{2} \mathrm{O}$ & 2,1 \\
\hline
\end{tabular}

Tabela 2: Composição da solução-estoque II para preparo de água do mar artificial [25]

\begin{tabular}{c|c}
\hline REAGENTE & CONCENTRAÇÃO $\left(\mathbf{g} \cdot \mathbf{L}^{-1}\right)$ \\
\hline $\mathrm{KCl}$ & 69,5 \\
\hline $\mathrm{NaHCO}_{3}$ & 20,1 \\
\hline $\mathrm{KBr}$ & 10,0 \\
\hline $\mathrm{H}_{3} \mathrm{BO}_{3}$ & 2,7 \\
\hline $\mathrm{NaF}$ & 0,3 \\
\hline
\end{tabular}


Inicialmente, foram dissolvidos 245,34 g de cloreto de sódio e 40,94 g de sulfato de sódio anidro a 8 L de água destilada. Em seguida, foram vagarosamente adicionados $200 \mathrm{~mL}$ da solução-estoque I sob agitação magnética e $100 \mathrm{~mL}$ da solução-estoque II. A nova solução foi então diluída até o volume de $10 \mathrm{~L}$ e seu pH foi ajustado, no momento do uso nos testes de adsorção, para 8,2 por meio de adição de hidróxido de sódio $0,1 \mathrm{~mol} / \mathrm{L}$ de acordo com o procedimento descrito na mesma norma [25].

Finalmente, o contaminante simulado de petróleo foi preparado pela adição de $5 \mathrm{~mL}$ de gasolina comercial do tipo $\mathrm{C}$ a $150 \mathrm{~mL}$ de água doce ou salgada para posterior teste de adsorção nas duas condições.

\subsection{Ensaios de adsorção}

Para a verificação da influência de parâmetros físico-químicos na biossorção da solução sintética de contaminante, os ensaios de adsorção ocorreram em triplicata e foram subdivididos em testes com variações de tamanho de partícula de biomassa, temperatura do contaminante simulado e tempo de adsorção.

Em todos os ensaios foram adicionados $0,500 \mathrm{~g}$ de biomassa a $155 \mathrm{~mL}$ de solução contaminante artificial, sendo o sistema agitado a $700 \mathrm{rpm}$ com base em protocolo experimental adaptado de Nwadiogbu et al. [26]. Santos et al. [11] avaliaram a influência da agitação sobre a capacidade de adsorção de hidrocarbonetos leves de petróleo por diferentes biomassas e concluíram que este é um parâmetro que não exerce significativa influência sobre a capacidade de biossorção do contaminante empregando agitação próxima à utilizada neste trabalho (1000 rpm). Ao final de cada experimento, a biomassa impregnada de gasolina foi filtrada a vácuo num funil de Büchner e teve sua massa aferida numa balança analítica Bel Engineering modelo S203.

Com vistas à maior precisão do resultado obtido, os papéis de filtro utilizados na filtração foram anteriormente encharcados com amostra de solução contaminante e, imediatamente, pesados. Dessa maneira, foi possível eliminar a fração de contaminante absorvida pelo papel e considerar no cálculo apenas o montante de fato adsorvido pela biomassa. Além disso, o bioadsorvente foi submetido ao contato com apenas água doce e apenas água salgada por 1 hora e a $700 \mathrm{rpm}$ para que a fração por ele adsorvida fosse descontada no cálculo de adsorção da solução contaminante.

A capacidade de adsorção da biomassa $(\mathrm{Q})$ foi determinada pela equação 1 , onde " $\mathrm{m}_{0}$ " é a massa do biomaterial antes da adsorção e " $m_{\mathrm{f}}$ " é a massa do material impregnado de óleo ao final da reação.

$$
Q=\frac{m_{f}-m_{0}}{m_{0}}
$$

Com vistas à avaliação da capacidade da biomassa de adsorção de compostos orgânicos, foi estudado inicialmente o comportamento adsortivo da casca frente aos seguintes corantes orgânicos: rodamina B, amarelo tartrazina e azul de metileno (cujas fórmulas estruturais são representadas nas Figuras 1, 2 e 3 respectivamente). Ademais, a diferença estrutural dos corantes permite inferir sobre a capacidade de o adsorvente reter moléculas de diferentes tamanhos por adsorção física.<smiles>CCN(CC)C1CCC2C(c3ccccc3C(=O)O)=C3CCC(=[N+](CC)CC)CC3OC2C1</smiles>

Figura 1: Estrutura química do corante rodamina B.<smiles>O=[N+]([O-])c1ccc(/N=N/c2c([N+](=O)[O-])nn(-c3cccc([N+](=O)[O-])c3)c2O)cc1</smiles> 
Figura 2: Estrutura química do corante amarelo tartrazina<smiles></smiles>

Figura 3: Estrutura química do corante azul de metileno

Para tanto, inicialmente foram preparadas soluções de diferentes concentrações (C1, C2, C3, C4, C5 e C6,) para obtenção de curvas de calibração dos corantes, conforme indicado na Tabela 3.

Tabela 3: Concentração das soluções utilizadas para obtenção da curva de calibração

\begin{tabular}{c|c|c|c}
\hline CONCENTRAÇÃO & RODAMINA B $\left(\mathbf{m g} \cdot \mathbf{m L}^{-1}\right)$ & $\begin{array}{c}\text { AMARELO TARTRAZINA } \\
\left(\mathbf{m g} \cdot \mathbf{m L}^{-1}\right)\end{array}$ & AZUL DE METILENO (mg.mL $\left.\mathbf{m}^{-1}\right)$ \\
\hline $\mathrm{C}_{1}$ & 0,187 & 1,25 & 0,313 \\
\hline $\mathrm{C}_{2}$ & 0,375 & 2,50 & 0,625 \\
\hline $\mathrm{C}_{3}$ & 0,750 & 5,00 & 1,25 \\
\hline $\mathrm{C}_{4}$ & 1,50 & 10,0 & 2,50 \\
\hline $\mathrm{C}_{5}$ & 3,00 & 20,0 & 5,00 \\
\hline $\mathrm{C}_{6}$ & 6,00 & 40,0 & 10,0 \\
\hline
\end{tabular}

Valores de absorbância das soluções de corante foram obtidas num espectrofotômetro Nova modelo 1105 , considerando os comprimentos de onda iguais a $550 \mathrm{~nm}$ para soluções de rodamina $\mathrm{B}, 430 \mathrm{~nm}$ para amarelo tartrazina e $665 \mathrm{~nm}$ para azul de metileno. De posse desses valores, foi possível a obtenção da curva de calibração para cada um dos corantes. Em seguida, $0,1 \mathrm{~g}$ de biomassa de eucalipto foi exposto ao volume de $7 \mathrm{~mL}$ de cada uma das soluções de corante em tubos de ensaio. Os tubos foram colocados em erlenmeyers de $250 \mathrm{~mL}$ e o sistema foi submetido a agitação num shaker a $100 \mathrm{rpm}$ e $25^{\circ} \mathrm{C}$ por 24 horas.

Ao fim do tempo de reação, fez-se novamente a leitura de absorbância das amostras no espectrofotômetro e, associando os valores obtidos com a curva de calibração, foi possível determinar a concentração final de cada solução.

Após se avaliar a capacidade de a biossorção dos corantes orgânicos pela casca de eucalipto, esta biomassa foi analisada frente à adsorção de gasolina comercial do tipo C, para tanto foram estudadas as influências da granulometria da biomassa $(0,3 \mathrm{~mm}, 0,6 \mathrm{~mm}$ e 2,36 mm), da temperatura do contaminante simulado $\left(7^{\circ} \mathrm{C}\right.$ e $\left.20^{\circ} \mathrm{C}\right)$ e do tempo de adsorção (30, 60 e 120 minutos).

Por fim, o desempenho adsortivo da biomassa de eucalipto foi comparado ao de outros adsorventes comerciais (nas condições ótimas definidas pelos testes anteriores): carvão ativo, terra diatomácea e vermiculita.

\section{RESULTADOS E DISCUSSÃO}

De acordo com os resultados obtidos pelo método BET, foi constatado o diâmetro médio de poros igual a 78,549 A, ou seja, a amostra é predominantemente constituída pela classe de mesoporos, como também observado por Sun et al. [27]. Além disso, verificou-se que os poros apresentaram tamanho pouco variado, isto é, o adsorvente apresentou estrutura regular, com os volumes de poro associados a diâmetros predominantemente inferiores a $98,580 \AA$.

Apesar do diâmetro médio de poros exibido pelo adsorvente, o material apresentou baixos valores de área superficial específica $\left(0,3994 \mathrm{~m}^{2} / \mathrm{g}\right)$ e de volume total de poros $\left(0,00078 \mathrm{~cm}^{3} / \mathrm{g}\right) \mathrm{se}$ comparado ao obtido por outros autores [28, 29], características que se impõem como possíveis barreiras à física deste material. No entanto, à hidrofobicidade da biomassa lignocelulósica (verificada por sua baixa molhabilidade em soluções aquosas) e à sua rugosidade também são atribuídas a eficiência de adsorção [30], o que poderia justificar o emprego da casca de eucalipto como adsorvente de hidrocarbonetos de petróleo.

As imagens de Microscopia Eletrônica de Varredura na figura 4 mostram a presença de feixes de fibras da madeira de eucalipto dotadas de compartimentos lamelares similares a poros, como também observa- 
do por Dave et al. [28], apresentando fraturas transversais provavelmente ocasionadas pelo impacto mecânico no processo de trituração sofrido pelo adsorvente de modo a causar a exposição da celulose por aumento de sua rugosidade, importante característica para a eficiência adsortiva desta biomassa [30].

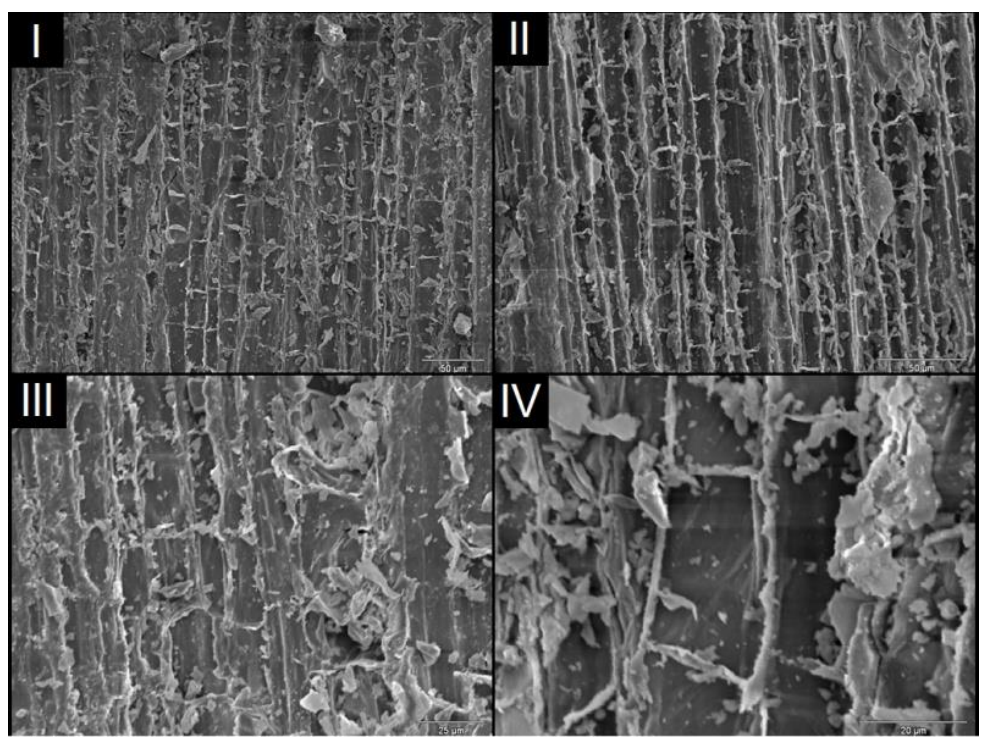

Figura 4: Microscopia Eletrônica de Varredura da casca de eucalipto em ampliações de 350 (I), 500 (II), 750 (III) e 1500 vezes (IV).

Para a caracterização da biomassa de casca de eucalipto, o material foi a priori testado para a adsorção de corantes orgânicos. Então, obteve-se uma curva de calibração para cada um desses compostos e estabelecida a correlação entre as suas concentrações e absorbâncias, de modo que foram obtidos, respectivamente, para rodamina B, amarelo tartrazina e azul de metileno, as equações 1, 2 e 3 e seus coeficientes de regressão linear $\mathrm{R}^{2}$ iguais a 0,9999, 0,9991 e 0,9916.

$y_{R}=0,213 x_{R}-0,0043$

$y_{T}=0,0313 x_{T}+0,0138$

$y_{A}=0,1655 x_{A}+0,0747$

Onde a variável "y" se refere ao valor de absorbância, " $x$ " à concentração de corante na solução e os índices "R", "T" e "A" associam as variáveis à rodamina $B$, amarelo tartrazina e azul de metileno, nesta ordem.

Os valores de correlação linear próximos de 1,0000 para todos os casos indicam íntima relação entre os parâmetros absorbância e concentração de corante em solução, revelando a boa qualidade e precisão da curva de calibração.

No tocante à adsorção dos três corantes (Figura 5) pela biomassa de eucalipto in natura, a quantidade adsorvida dessas substâncias foi calculada com base nas equações geradas no procedimento de calibração e considerando as diferentes concentrações testadas. 


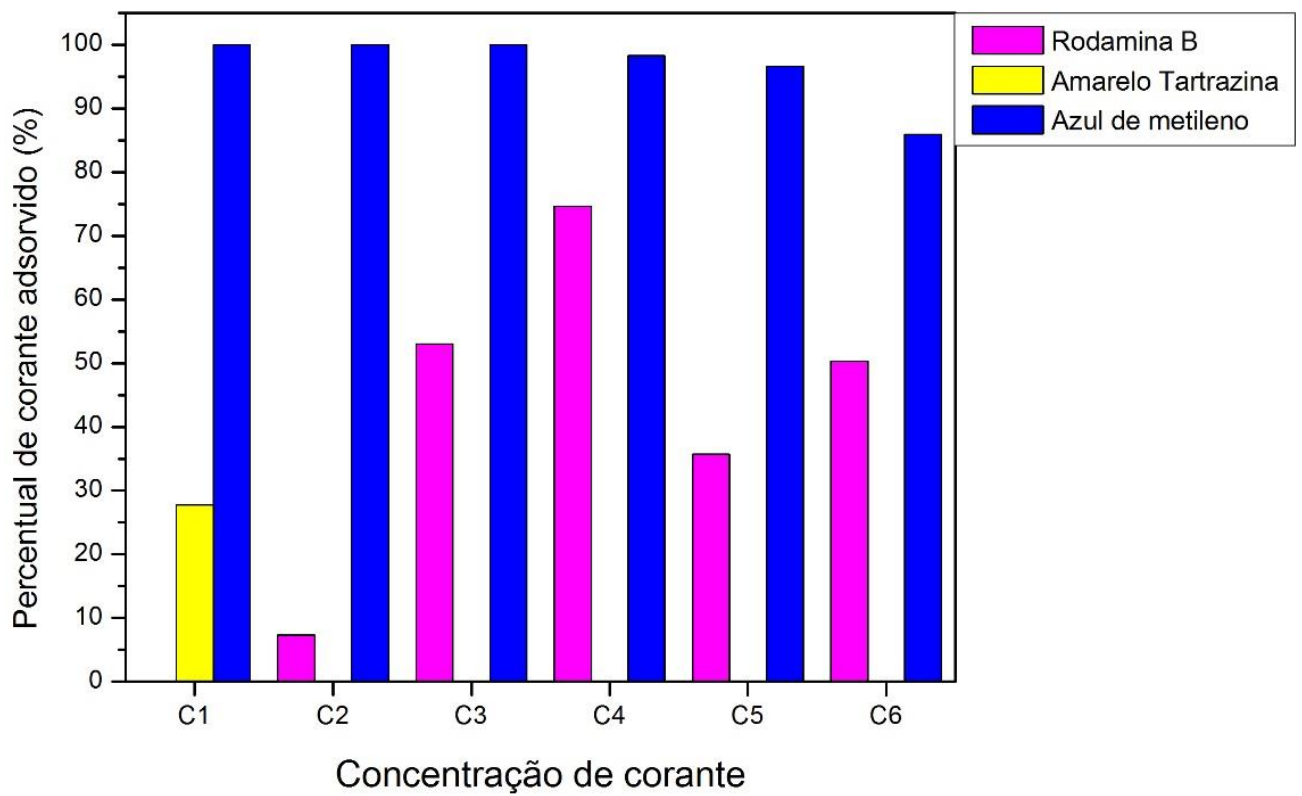

Figura 5: Porcentagem de adsorção de corantes orgânicos eucalipto rodamina B, amarelo tartrazina e azul de metileno pela biomassa de eucalipto

Diante dos resultados obtidos, verificou-se a capacidade de a biomassa de eucalipto adsorver o azul de metileno em todas as concentrações testadas, mas especialmente naquelas mais baixas, bem como a ineficiência na remoção de amarelo tartrazina e baixos valores de biossorção do corante rodamina $\mathrm{B}$. Considerando a característica iônica dos corantes, os resultados de adsorção para rodamina B e azul de metileno podem estar associados ao fato de esses serem corantes catiônicos, cuja porção de carga positiva está localizada na extremidade das moléculas, o que propicia a maior interação dessas substâncias com os grupos hidroxila, principalmente, da celulose e lignina, por meio de ligações de hidrogênio.

Além disso, a maior adsorção do azul de metileno provavelmente se atribui ao menor tamanho da molécula do referido corante orgânico, o que torna facilitada sua permeação pelos poros da biomassa de eucalipto, como também reduz os efeitos de impedimento estéril de sua molécula de modo a tornar os átomos de carbono de sua estrutura mais suscetíveis às ligações covalentes com outros átomos. Sun et al. [27] reportaram comportamento semelhante ao estudarem a adsorção de azul de metileno utilizando diferentes bioadsorventes, entre eles a biomassa de eucalipto, verificando que os mesoporos desse material apresentam diâmetro de ordem de grandeza próxima ao comprimento da molécula do corante. Ainda, ao estudarem a biossorção de corantes como azul de metileno e amarelo tartrazina, Dotto et al. [31] destacaram o fato de que moléculas com maior cadeia carbônica e de estrutura mais ramificada causam maior dificuldade de os corantes se difundirem pela material adsorvente. Desta maneira, foi possível verificar que, embora a casca de eucalipto tenha apresentado mesoporos de baixa área superficial, o tamanho de diâmetro médio dessas cavidades foi suficiente para reter os corantes de menores cadeias carbônicas, característica que torna este material promissor para aplicação na remoção de derivados de petróleo, uma vez que a gasolina comercial empregada como contaminante neste trabalho, por exemplo, é composta por hidrocarbonetos leves, contendo de 4 a 16 átomos de carbono e alguns compostos de enxofre [32], elemento também presente nos corantes azul de metileno e amarelo tartrazina.

Comprovada a capacidade de a biomassa de eucalipto adsorver compostos orgânicos, o adsorvente foi estudado quanto aos parâmetros físico-químicos que influenciam a biossorção de hidrocarbonetos leves de petróleo. Em relação à influência da granulometria, verifica-se pelo gráfico da Figura 6 que, para ambos as soluções de águas doce e salgada, os menores tamanhos de partícula de favoreceram a biossorção, tendo sido observados maiores valores de adsorção para as amostras de menor tamanho de partícula (0,3 mm).

Teste $t$-student foi conduzido num intervalo de confiança de $95 \%$ a fim de se avaliar a influência da granulometria em meio às águas doce e salgada. Assim, foi constatado que não houve variação estatisticamente significativa para a adsorção em água doce ou salgada varaiando-se o tamanho médio de partícula do biossorvente, obtendo-se valor-p de 0,177, 0,795 e 0,431 respectivamente para as gralunometrias de 0,3,0,6 e $2,36 \mathrm{~mm}$. 


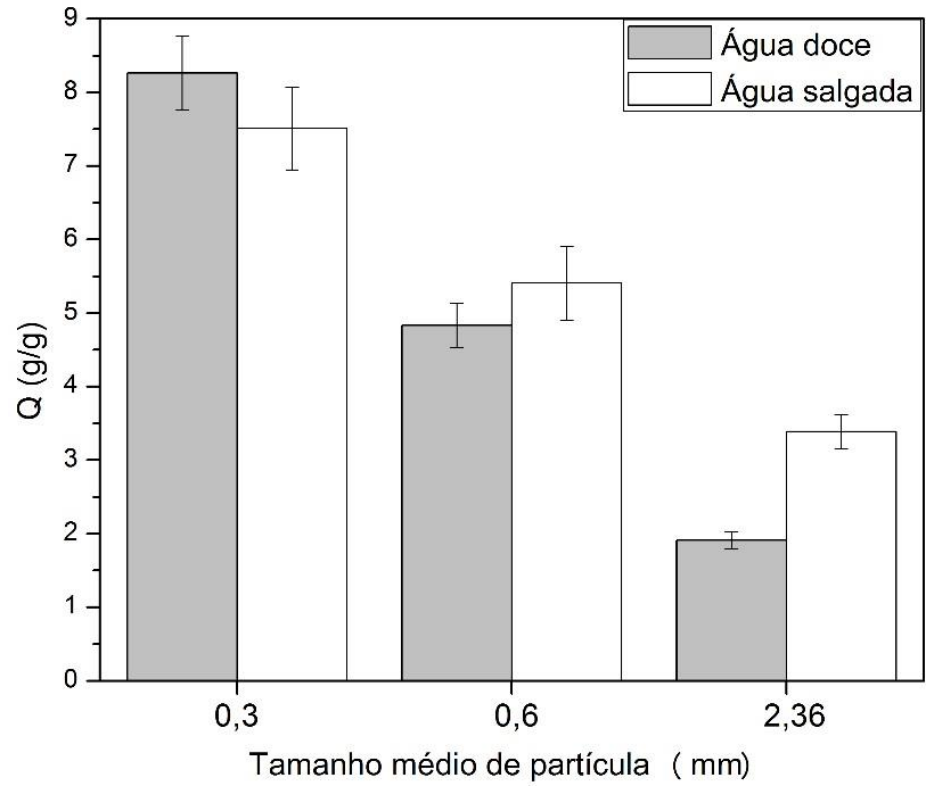

Figura 6: Influência da granulometria na biossorção do contaminante em água doce e em água salgada

A maior capacidade de adsorção da biomassa com os menores tamanhos de partícula eram esperados, pois nessas estão presentes as maiores áreas superficiais e de contato, expondo à solução contaminada a maior área disponível para adsorção, como também relatam Araujo et al. [33], que estudaram a adsorção de óleo diesel utilizando flakes de garrafa PET.

Quando avaliada a influência da temperatura (Figura 7), notou-se que a quantidade de óleo adsorvido apresentou ligeiras alterações entre as temperaturas de $7^{\circ} \mathrm{C}$ e $20^{\circ} \mathrm{C}$, fato verificado a partir de um teste estatístico $t$-student para intervalo de confiança de $95 \%$, sendo obtidos valores-p de 0,994 quando comparados os resultados de adsorção em água doce nas duas temperaturas e de 0,827 para água salgada. Deste modo, foi possível inferir que esse parâmetro não interferiu de forma expressiva na capacidade da biomassa de interagir com a solução contaminante.

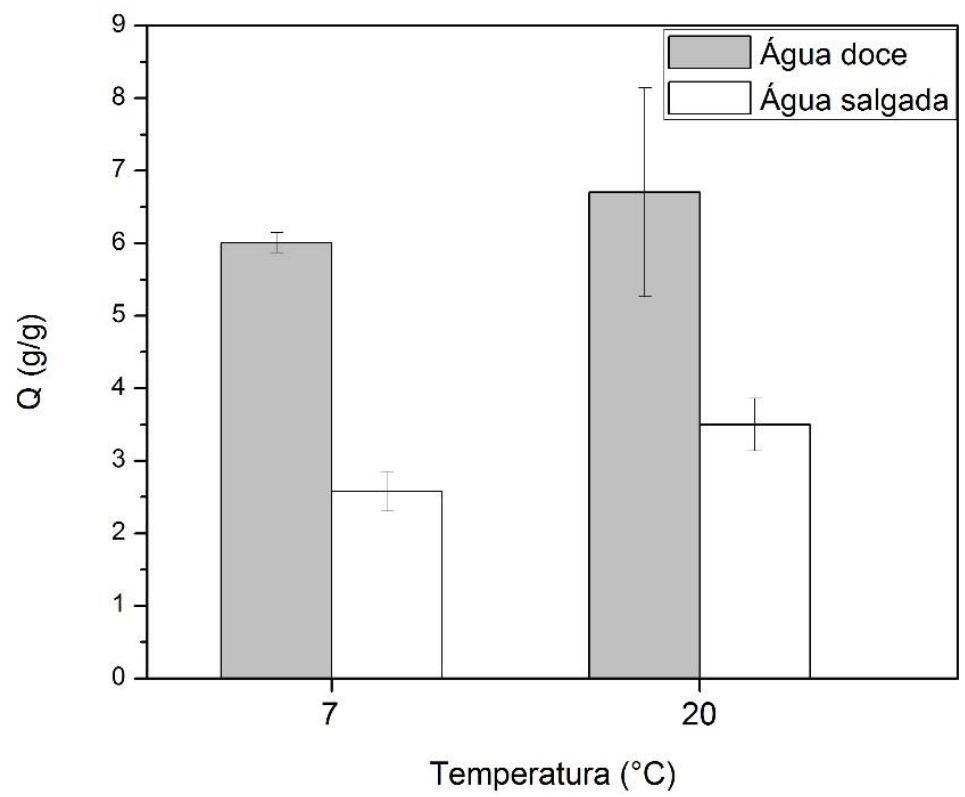

Figura 7: Influência da temperatura na biossorção do contaminante em água doce e em água salgada

Foi possível verificar ainda que a maior temperatura contribuiu para a adsorção no ambiente de água 
doce e desfavoreceu o fenômeno na solução de água do mar artificial. Possivelmente na maior temperatura os sais presentes na solução de água do mar artificial passam a interagir com os poros da biomassa por meio de ligações eletrostáticas principalmente os grupos hidroxila da madeira de eucalipto, dado o aumento de energia cinética do sistema, ao passo que na temperatura de $7^{\circ} \mathrm{C}$ os sítios adsortivos da biomassa podem estar menos sucestíveis ao contato com os íons da solução, facilitando a maior interação com as moléculas do óleo contaminante. Segundo Motta et al. [33], este comportamento também ocorre em processos de separação por membranas, onde o fouling, que consiste no acúmulo e deposição de partículas na superfície dessas membranas, apresenta-se como uma barreira à capacidade de separação das membranas por mecanismos de bloqueio dos poros e precipitação de sais sobre sua superfície.

O mesmo fenômeno não ocorreu em água doce, entretanto, provavelmente pela menor quantidade de substâncias que concorrem pela superfície adsortiva da casca de eucalipto, de modo que o efeito mais expressivo neste caso é o de aumento do número de colisões efetivas de hidrocarbonetos na superfície do adsorvente estabelecendo ligação química, fato ocasionado pelo aumento da temperatura.

Quanto ao tempo de reação, cujos resultados são expressos no gráfico da Figura 8, para o sistema de água doce, a adsorção foi crescente à medida que o intervalo de tempo aumentava, obtendo-se maiores valores dessa propriedade para o maior tempo de reação (120 minutos). Contrariamente, o mesmo fenômeno não foi observado para a água salgada, onde a interação entre a biomassa e o contaminante foi desfavorecida com o aumento do período de contato.

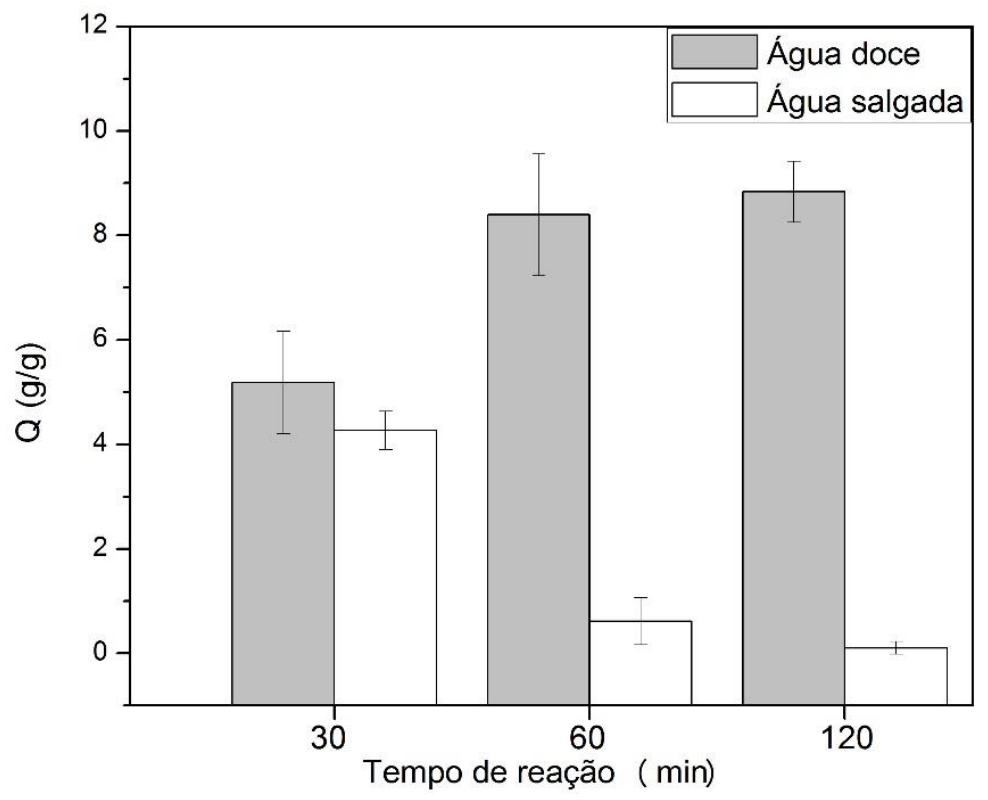

Figura 8: Influência do tempo de reação na biossorção do contaminante em água doce e em água salgada

Pela análise do gráfico da Figura 7, verificou-se que houve maior adsorção de contaminantes no sistema de água doce e, de forma ainda mais acentuada, o mesmo fenômeno foi observado na Figura 8. Tal fato provavelmente pode ser justificado pela competição dos sítios adsortivos da biomassa pelos hidrocarbonetos contaminantes (porção hidrofóbica rica em carbono das estruturas celulósicas principalmente) e pela excessiva presença de sais dissolvidos na água de simulação marítima, ocasionando reação iônica com a porção hidrofílica do eucalipto. Assim, quanto maior o tempo de contato da biomassa com a solução contaminante, possivelmente maior foi a adesão dos sais da solução marítima simulada, em virtude das possibilidades de ligação química existentes entre as porções de alta eletronegatividade das moléculas de celulose (principalmente pelos grupos hidroxila) e os íons correspondentes aos mencionados sais.

Quanto à comparação estabelecida entre as capacidades de adsorção da solução contaminante simulada pela biomassa de eucalipto e pelos adsorventes: carvão ativo, vermiculita e terra diatomácea, sob as condições ótimas de temperatura e tempo de contato definidas quando utilizado o bioadsorvente objeto de estudo deste trabalho, seu potencial de adsorção foi superior ao dos demais em ambos os ambientes de águas doce e salgada (Figura 9). 


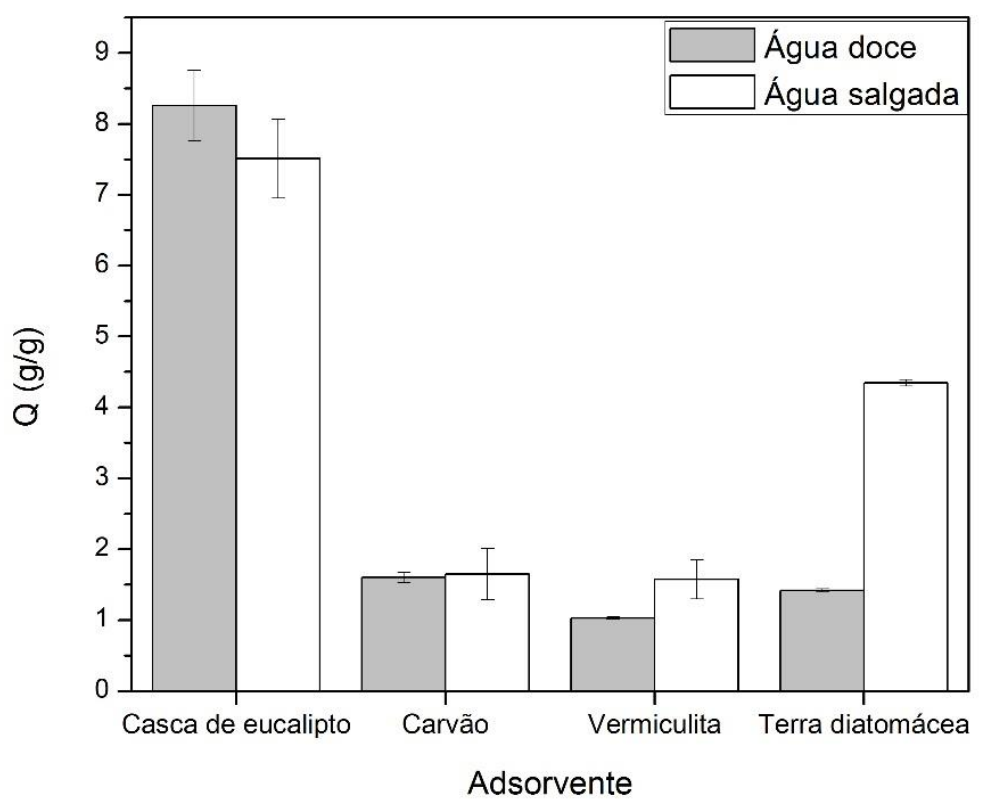

Figura 9: Comparação da capacidade de adsorção da biomassa de eucalipto com a de outros adsorventes.

Cabe ainda ressaltar que a capacidade de adsorção constatada para a biomassa de eucalipto foi equiparável a valores reportados por Santos et al. [11], que em condições experimentais otimizadas obtiveram potenciais de adsorção de hidrocarbonetos leves de petróleo de 8,93 g.g ${ }^{-1}$ para mesocarpo de coco, 8,86 g.g ${ }^{-1}$ para bagaço de cana, 6,55 g.g $\mathrm{g}^{-1}$ para serragem de madeira e $6,48 \mathrm{~g} \cdot \mathrm{g}^{-1}$ para sabugo de milho. Além disso, a casca de eucalipto apresentou maior eficiência de remoção dos contaminantes do que aquela apresentada por argilas Bofe natural $\left(1,11 \mathrm{~g} \cdot \mathrm{g}^{-1}\right)$ e organofílica $\left(5,23 \mathrm{~g} \cdot \mathrm{g}^{-1}\right)$, bem como para argilas Chocolate B natural $(0,70$ g. $\left.\mathrm{g}^{-1}\right)$ e organofílica $\left(2,21 \mathrm{~g} \cdot \mathrm{g}^{-1}\right)[35]$.

\section{CONCLUSÕES}

Diante dos resultados de adsorção de contaminante nos ambientes simulados, foi possível verificar que a biomassa de eucalipto foi capaz de adsorver, entre os corantes, principalmente o azul de metileno devido à sua pequeno tamanho de molécula e a rodamina. Quanto aos hidrocarbonetos leves da gasolina comercial derivada de petróleo, a casca foi capaz de remover parte dos hidrocarbonetos presentes nas soluções contaminantes nas diferentes condições a que foi submetida. Além disso, seu potencial adsortivo foi superior ao de outros adsorventes testados nas mesmas condições, o que reafirma sua possibilidade de emprego para a remoção de compostos orgânicos hidrofóbicos. Entretanto, a baixa área superficial e o pequeno volume de poros da biomassa de eucalipto se apresentam como limitantes à sua aplicação enquanto adsorvente, além de que a presença de diversos grupos hidroxila na estrutura química do material, em virtude da alta porcentagem de lignina e celulose, favorece também a adsorção de água pela casca, o que é um inconveniente em se tratando de um produto com vistas à remoção de compostos apolares de ambientes aquáticos.

\section{AGRADECIMENTOS}

Os autores deste trabalho agradecem ao professor Alan Rodrigues Teixeira Machado do Centro Universitário de Belo Horizonte (UniBH) pelo apoio técnico dispensado nesta pesquisa, à empresa Vermiculita Isolantes Termo-acústicos Ltda. e à Fundação Ezequiel Dias por cederem os adsorventes vermiculita e terra diatomácea utilizados neste trabalho, e aos senhores Sérgio Carneiro dos Reis e Eduardo Antônio de Carvalho pelo apoio com as análises de BET e MEV no CDTN. 


\section{BIBLIOGRAFIA}

[1] ORGANIZATION of the Petroleum Exporting Countries, OPEC, "World Oil Outlook”, out., 2016. Disponível em: 〈http://www.opec.org>. Acessado em: 10 jan. 2017.

[2] AGÊNCIA Nacional do Petróleo, Gás Natural e Biocombustíveis, ANP, “Anuário estatístico brasileiro do petróleo, gás natural e biocombustíveis: 2016”, Rio de Janeiro, 2016.

[3] CALDAS, A. S., VIANA, Z. C. V., SANTOS, V. L. C. S., "Fibras de Cocos nucifera como sorvente de petróleo em ambiente marinho", Acta brasiliensis, v.1, n.1, pp.13-18, 2017.

[4] INTERNATIONAL Tanker Owners Pollution Federation, ITOPF, “Apresenta informações, publicações, conselhos e assistência técnica com relação a respostas a poluição por vazamentos de óleo", 2006. Disponível em: <http://www.itopf.com>. Acessado em: 10 jan 2017.

[5] SHENKMANN, L., STOKSTAD, E., “Gulf oil disaster”, AAAS, v. 328, pp. 1214-125, jun, 2010.

[6] SONG, S., SHON, Z., KIM, Y., et al., "An oil spill accident and its impact on ozone levels in the surrounding coastal regions", Atmospheric Environment, n.45, pp. 1312-1322, 2011.

[7] SOUZA, R. S., LIMA, L. M. R., SILVA, V. L. M. M., “Adsorção de óleo diesel em sistema de leito diferencial com biomassa bagaço de cana-de-açúcar", Revista Eletrônica de Materiais e Processos, v.6, n. 2, pp.123-126, 2011.

[8] BONI, H. T., OLIVEIRA, D., SOUZA, A. A. U., et al., "Bioadsorption by sugarcane bagasse for the reduction in oil and grease contente in aqueous efluente", International Journal of Environmental Science and Technologoy, v. 13, pp.1169-1176, 2016.

[9] BONI, H. T., Aplicação de biomassa na redução do teor de óleos e graxas presentes em efluentes aquosos. Dissertação de M.Sc.. Departamento de Engenharia Química e Engenharia de Alimentos, UFSC. Florianópolis, 2012.

[10] COSTA, M. T., QUINTELA, D. U., PEITER, A. S., et al., "Estudo da cinética da adsorção no tratamento de água de produção de petróleo utilizando bagacilho como agente adsorvente", Revista de Ciências Exatas, v.33, n.1, pp. 53-61, 2014.

[11] SANTOS, E. G., ALSINA, O. L. S., SILVA, F. L. H., "Desempenho de biomassas na adsorção de hidrocarbonetos leves em efluentes aquosos", Química Nova, v. 30, n. 2, p. 327-331, 2007.

[12] YOUNIS, S. A., EL-GENDY, N. S., EL-AZAB, W. I., et al., "Kinetic, isotherm, and thermodynamic studies of polycyclic aromatic hydrocarbons biosorption from petroleum refinery wastewater using spent waste biomass", Desalination and water treatment, v.56, pp. 3013-3023, 2015.

[13] ASSOCIAÇÃO Brasileira de Produtores de Florestas Plantadas, ABRAF, Anuário Estatístico da ABRAF 2012 - Ano base 2011, Brasília, 2012.

[14] TAHIR, M. A., BHATTI, H. N., IQBAL, M., "Solar red and brittle blue direct dyes adsorption onto Eucalyptus angophoroides bark: equilibrium, kinetics and thermodynamic studies", Journal of Environmental Chemical Engineering, v.4, 2, 2431-2439, 2016.

[15] AFROZE, S., SEN, T. K, ANG, M., et al., "Adsorption of methylene blue dye from aqueous solution by novel biomass Eucalyptus sheathiana bark: equilibrium, kinetics, thermodynamics and mechanism", Desalination and water treatment, v.57, n.13, 2016.

[16] ZAZOULI, M. A., AZARI A., DEHGHAN, S., et al., "Adsorption of methylene blue from aqueous solution onto activated carbons developed from eucalyptus bark and Crataegus oxyacantha core", Water Science and Technology, v.74, n.9, pp. 2021-2035, 2016.

[17] MUSTAFA, J., KAUSAR, A., BHATTI, H. N., ILYAS, S., "Adsorption of methylene blue from aqueous solution onto activated carbons developed from eucalyptus bark and Crataegus oxyacantha core", Desalination and water treatment, v.57, 31, 2016.

[18] AFROZE, S., SEN, T. K., ANG, H. M., “Adsorption removal of zinc (II) from aqueous phase by raw and base modified Eucalyptus sheathiana bark: Kinetics, mechanism and equilibrium study", Process Safety and Environmental Protection, v.102, pp. 336-352, 2016.

[19] SWAMI, D. N., GUPTA, S. K., "Adsorption Kinetics for the Removal of Chromium(VI) from Synthetic Waste Water Using Adsorbent Derived from Saw Dust, Bark and Rice Husk", Recent advances in Chemical Engineering, pp. 153-163, 2016.

[20] BHAWNANI, A., GUPTA, S. K., "Removal of Cr(VI) from waste water using root of eucalyptus tree", International Journal of Engineering Technology Science and Research, v.3, n.11, 2016. 
[21] SIHABUDEEN, M. M., ALI, A. A., HUSSAIN, Z., "Removal of heavy metals from ground water using eucalyptus carbon as adsorbent", International Journal of ChemTech Research, v.9, 3, 254-257, 2016.

[22] BRAGATTO, J., Avaliação do potencial da casca de Eucalyptus spp. para a produção de bioetanol. Tese de D.Sc.. Universidade de São Paulo. Piracicaba, 2010.

[23] BRANDÃO, P. C., Avaliação do uso do bagaço de cana como adsorvente para a remoção de contaminantes, derivados do petróleo, de efluentes, Dissertação de M.Sc.. Uberlândia. Universidade Federal de Uberlândia, 2006.

[24] AMERICAN Public Health Association, APHA, American Water Works Association, AWWA, Water Environment Federation, WEF, Standard Methods for the Examination of Water and Wastewater, Eaton, A. D., L. S. Clesceri, A. E. Greenberg (Ed.), 20th ed. Washtington, D. C., 2005.

[25] AMERICAN Society for Testing and Materials.Standard, ASTM, Specification for substitute ocean water-Designation D-1141-98, 1998.

[26] NWADIOGBU, J.O., AJIWE, V.I.E., OKOYE, P.A.C., "Removal of crude oil from aqueous medium by sorption on hydrophobic corncobs: equilibrium and kinetic studies", Journal of Taibah University for Science, v.10, n.1, pp.56-63, 2016.

[27] SUN, L., WAN, S., LUO, W., "Biochars prepared from anaerobic digestion residue, palm bark, and eucalyptus for adsorption of cationic methylene blue dye: characterization, equilibrium, and kinetic studies", Bioresource Technology, v. 140, pp. 406-413, 2013.

[28] DAVE, P. N., KAUR, S., KHOSLA, E., "Removal of Eriochrome black-T by adsorption on to eucalyptus bark using green technology", Indian Journal of Chemical Technology, v. 18, pp.53-60, 2011.

[29] SARIN, V., PANT, K. K., "Removal of chromium from industrial waste by using eucalyptus bark", Bioresource Technology, v.97, pp. 15-20, 2006.

[30] SAATKAMP, R. H., Adsorção de azul de metileno em serragem de eucaliptos in natura e pós tratamento por plasma frio, Relatório de pesquisa, Universidade Federal de Santa Catarina, 2016.

[31] DOTTO, G. L., VIEIRA, M. L. G., GONÇALVES, J. O., et al., "Remoção dos corantes azul brilhante, amarelo crepúsculo e amarelo tartrazina de soluções aquosas utilizando carvão ativado, terra ativada, terra diatomácea, quitina e quitosana: estudos de equilíbrio e termodinâmica”, Química Nova, v. 34, n. 7, pp. 1193-1199, 2011.

[32] BUENO, R. S., LIMA, C. B., SILVA, M. A., et al., “Avaliação das propriedades físicas e físicoquímicas da gasolina "C" comum comercializada em alguns postos na cidade de Uberaba-MG”, In: $8^{\circ}$ Encontro de Tecnologia da UNIUBE, Uberaba/MG, 2014.

[33] ARAUJO, M. J. F., MULliNARI, D. R., ARAUJO, M. V. F., "Sorção de óleo diesel a partir da reutilização de garrafas PET”, Cadernos UniFOA, n. 29, p. 21-31, 2015.

[34] MOTTA, A. R. P., BORGES, C. P., KIPERSTOK, A., et al., "Tratamento de água produzida do petróleo para remoção de óleo por processos de separação por membranas: revisão", Engenharia Sanitária e Ambiental, v.18, n.1, p. 15-26, 2013.

[35] CUNHA, R.S.S., MOTA, J.D., RODRIGUES, M.G.F., “Obtenção e aplicação de argilas modificadas na capacidade de adsorção de efluente petrolífero”, In: XX Congresso Brasileiro de Engenharia Química, Florianópolis/SC, 2014. 